\title{
Audit activity and quality of completed audit projects in primary care in Staffordshire
}

\author{
Ruth Chambers, Susan Bowyer, Ian Campbell
}

\begin{abstract}
Objectives-To survey audit activity in primary care and determine which practice factors are associated with completed audit; to survey the quality of completed audit projects.

Design-From April 1992 to June 1993 a team from the medical audit advisory group visited all general practices; a research assistant visited each practice to study the best audit project. Data were collected in structured interviews.
\end{abstract}

Setting-Staffordshire, United Kingdom. Subjects-All 189 general practices.

Main measures-Audit activity using Oxford classification system. Quality of best audit project by assessing choice of topic; participation of practice staff; setting of standards; methods of data collection and presentation of results; whether a plan to make changes resulted from the audit; and whether changes led to the set standards being achieved.

Results-Audit information was available from 169 practices $(89 \%)$. 44(26\%) practices had carried out at least one full audit; $40(24 \%)$ had not started audit. Mean scores with the Oxford classification system were significantly higher with the presence of a practice manager $(2 \cdot 7(95 \%$ confidence interval $2 \cdot 4$ to $2 \cdot 9)$ $v 1.2(0.7$ to 1.8$), p<0.0001)$ and with computerisation $(2 \cdot 8(2.5$ to $3 \cdot 1) \quad v 1.4$ $(0.9$ to $2 \cdot 0), p<0 \cdot 0001)$, organised notes $(2 \cdot 6(2 \cdot 1$ to $3 \cdot 0) v 1 \cdot 7(7 \cdot 2$ to $2 \cdot 2), p=0 \cdot 03)$, being a training practice $(3 \cdot 5(3 \cdot 2$ to $3 \cdot 8) v$ $2 \cdot 1(1.8$ to $2 \cdot 4), p<0.0001)$, and being a partnership $(2 \cdot 8(2 \cdot 6$ to $3 \cdot 0) v 1 \cdot 5(1 \cdot 1$ to $2 \cdot 0)$, $p<0.0001)$. Standards had been set in 62 of the 71 projects reviewed. Data were collected prospectively in 36 projects and retrospectively in 35.16 projects entailed taking samples from a study population and 55 from the whole population. 50 projects had a written summary. Performance was less than the standards set or expected in 56 projects. 62 practices made changes as a result of the audit. 35 of the 53 that had reviewed the changes found that the original standards had been reached.

Conclusions-Evaluation of audit in primary care should include evaluation of the methods used, whether deficiencies were identified, and whether changes were implemented to resolve any problems found.

(Quality in Health Care 1995;4:178-183)

Keywords: audit activity, audit projects, primary care

\section{Introduction}

General practitioners have shown a mixed response $^{1-3}$ to the Department of Health's instruction ${ }^{4}$ to participate in medical audit. Some practices have been enthusiastic: a survey in Oxfordshire in 1991 found that only $21 \%$ of practices had never done any audit. ${ }^{1}$

But simple participation in medical audit is insufficient - the audit must be done well for it to be worth while. There have been calls for more evaluation of the medical audit programme in the United Kingdom, ${ }^{3}{ }^{5}$ but how is good quality audit defined? The Department of Health defined medical audit in its 1989 white paper as "the systematic critical analysis of the quality of medical care, including the resulting outcome and quality of life for the patient." 6 This definition does not specify that an improvement in the quality of care should actually or potentially result from medical audit, but this is frequently assumed to be its main purpose. Some reasons why audit does not necessarily lead to improvements in patient care are the absence of good leadership and communication, ${ }^{7}$ poor motivation ${ }^{7}$ or personal commitment, ${ }^{8}$ lack of necessary resources, ${ }^{9}$ and failure to identify why current practice fails to meet the standard. The white paper definition specifies critical analysis, and any audit project will need to include an adequate sample size, an unbiased method of sampling, and appropriate analysis. ${ }^{1011}$

In primary care the Oxford classification system (box) ${ }^{1}$ has been adopted by many medical audit advisory groups as an indicator of the quality of audit work being carried out. $^{2} 12$ An evaluation of the audit in Oxfordshire in 1991 that used this classification system found that only about one half of general practices undertaking it were performing full audit. ${ }^{1}$ An evaluation of audit

\begin{tabular}{|c|c|}
\hline \multicolumn{2}{|c|}{ Oxford classification system ${ }^{1}$} \\
\hline Code & Description \\
\hline I & Choose topic \\
\hline II & Set target standards \\
\hline III & Observe practice \\
\hline IV & $\begin{array}{l}\text { Compare performance with } \\
\text { targets }\end{array}$ \\
\hline V & Implement change, plan care \\
\hline VI & Repeat cycle \\
\hline Criterion & Criterion satisfied if: \\
\hline Full audit & Five of six codes present \\
\hline Partial audit & $\begin{array}{l}\text { Codes I and III present plus } \\
\text { either II or V }\end{array}$ \\
\hline Potential audit & Codes I and III present \\
\hline Planning audit & $\begin{array}{l}\text { Topic chosen and audit } \\
\text { definitely intended }\end{array}$ \\
\hline No audit & \\
\hline
\end{tabular}

Centre for Primary niversity of Keele, Stoke on Trent ST4 7JB lecturer

I C Statistical Services Wirral L63 0N

Ian Campbell, statistical consultant

Correspondence to: 
projects is itself an audit activity, and so can be categorised as an audit of structure, process, or outcome. ${ }^{14}$ On this basis, use of the Oxford classification system gives an audit of the process of audit as it does not include an assessment of outcome - that is, whether an improvement in patient care resulted. We used the Oxford classification system to evaluate the extent of medical audit activity by general practitioners in Staffordshire and to determine if there were any practice factors that were associated with more complete audit. We also reviewed completed audit projects in more depth, including choice of topic, participation of practice staff, setting of standards, methods of data collection and presentation of results, whether a plan to make changes resulted from the audit, and whether changes led to the set standards being achieved.

\section{Methods}

Between April 1992 and June 1993 medical audit in primary care in Staffordshire was reviewed through two visiting programmes. The aim was that all general practices in Staffordshire would first be visited by a team from the medical audit advisory group as part of an educational exercise and that there would be a second visit by the project research assistant to all of the practices that had completed at least one audit project to study the quality of audit in more depth. In the event, some practices refused a visit by the advisory group but agreed to be visited by the research assistant, and because of the logistics of visiting many practices in a limited time, a few practices were visited by the research assistant before being visited by the team.

VISITING PROGRAMME OF THE TEAM

All 189 general practices in Staffordshire were contacted first by letter and subsequently by telephone and were invited to participate in the visiting programme by the audit advisory group. Those that agreed were visited by a team consisting of a doctor and at least one audit facilitator who was not medically qualified. The team discussed audit with one or more general practitioner partners and any other interested staff to collect information on audit that had already been carried out, to educate, and to facilitate future audit. This was similar to the visiting programmes that were set up by other advisory groups in Great Britain at around the same time. Audits that had been carried out were classified according to the Oxford criteria (box). ${ }^{1}$ For the purposes of this project, the Oxford criteria were assigned the following scores: no audit 0 , planning audit 1 , potential audit 2 , partial audit 3 , and full audit 4 . The presence and status of any staff member(s) who willingly took the lead on audit ("audit enthusiast(s)") were also recorded. The patients' case notes were classified as fully organised (all in date order, appropriately filleted and with a summary card), partly organised (only some notes organised, or all notes only partly organised), or not organised. Information about the extent of computerisation of the practice, about training status, and about the presence of a practice manager was obtained from the family health services authority for all Staffordshire practices.

INDEPTH STUDY BY THE RESEARCH ASSISTANT The practices that indicated to the team (or to the project research assistant when contacted directly) that audit was occurring were invited to participate in the second visiting programme. This invitation was by letter followed by telephone calls. If agreement was received the project research assistant met one or more general practitioners with or without the practice manager and discussed the audit project that the practice regarded as the best out of those that they had completed (no guidance was given on the meaning of best). When several projects were thought to be of equal standard, the most recently completed project was selected. In a structured interview information was collected on the details of the individual projects, including the topic chosen, the reasons for carrying out the audit, the derivation of any standards used, the methods of data collection and sampling, the participation of practice staff at the various stages of the project, classification of the projects according to the Oxford criteria (box), ${ }^{1}$ the changes resulting from the projects, whether the changes had been successful, and whether any other benefits to the practice had occurred.

\section{ANALYSES}

Associations between the characteristics of the practices and the highest Oxford criterion of their audit projects were investigated by means of the Mann-Whitney $U$ test ${ }^{15}$ when two levels of the characteristic were compared - for example, a practice manager was either present or absent - or by Spearman's rank correlation coefficient ${ }^{16}$ when there were three levels of the characteristic - for example, organisation of notes was categorised as none, partial, or full. All statistical tests were two sided.

\section{Results}

AUDIT ACTIVITY IN STAFFORDSHIRE

Of the 189 Staffordshire practices, 151 agreed to be visited by the team. Eighteen of the 38 that refused a visit from the team agreed to be visited by the project research assistant, so that summary audit information was available on 169 of the practices (overall response rate $89 \%$ ).

The characteristics of the 189 practices are shown in table 1 . Forty (24\%) of the 169 practices that were visited had done no audit at all, while $44(26 \%)$ had carried out at least one full audit at some time according to the Oxford system (table 2 ).

Table 3 shows the level of audit activity in the practices broken down by six practice characteristics. Practices containing an audit enthusiast had in general performed more complete audit projects, as judged by the Oxford criteria ( $p<0.0001$, Mann-Whitney $\mathrm{U}$ test). Furthermore, those practices containing more than one audit enthusiast had higher Oxford criteria than those containing only a single enthusiast (mean score of 3.2 (95\% confidence interval 2.9 to 3.5$) v 2.6$ 
Table 1 Organisational characteristics of the 189 Staffordshire practices

\begin{tabular}{lc}
\hline Characteristic & No of practices \\
\hline Organisation of notes: & \\
Not organised & 36 \\
Partly organised & 43 \\
Fully organised & 47 \\
Not known & 63 \\
Computerisation: & \\
None & 45 \\
Used for administration only & 45 \\
Used for administration and clinical care & 90 \\
Not known & 9 \\
Audit enthusiast(s): & \\
General practitioner & 31 \\
Practice manager & 15 \\
General practitioner + one or more others & 45 \\
Practice manager + one or more others & 6 \\
Receptionist & 1 \\
None & 56 \\
Not known & 35 \\
\hline
\end{tabular}

^Not general practitioner.

( $2 \cdot 3$ to $3 \cdot 0), p=0 \cdot 01$, Mann-Whitney U test). More complete Oxford audit criteria were also significantly associated with the presence of a practice manager, greater use of computers, a higher level of organisation of the notes, training practices, and with partnerships as opposed to singlehanded practices (table 3). There was no evidence of a correlation between Oxford criteria and average practice list size.

QUALITY OF COMPLETED AUDITS

Forty three of the 189 Staffordshire practices either refused or repeatedly postponed a visit by the research assistant. Another 53 practices were not visited because they had either done no audit or had only recently started it and did not have a completed audit for evaluation; a

Table 2 Oxford criteria of the 189 practices' best ever audits

\begin{tabular}{lc}
\hline Oxford criteria & No of practices \\
\hline None & 40 \\
Planning & 10 \\
Potential & 22 \\
Partial & 53 \\
Full & 44 \\
Not known & 20 \\
\hline
\end{tabular}

further 22 practices were found on a visit by the research assistant to have completed no audit work. The remaining 71 practices had all completed at least one audit project, and the project that the practice designated as the best was reviewed by the research assistant (in eight cases the practice had two or more projects that it felt to be equally the best).

\section{Topics}

The 71 audits reviewed studied 39 different topics. The most popular areas were diabetes (14 practices), uptake of cytology screening (11), prescribing (11), and organisational aspects assessed by patient satisfaction surveys (14). Sixty eight of the 71 topics represented a local or practice concern; the three others were chosen because of a wider national issue. The main reasons for choosing the audit topics were local interest ( 33 practices), high cost (11), a common disease (10), high risk areas (five), and an issue of contention (two); three projects did not fit any of these categories. Table 4 shows the amount of participation of various categories of practice staff in the stages of the 71 audits studied.

\section{Standards}

Standards were set in 62 of the $71(87 \%)$ audit projects studied. Thirty four had set explicit standards, which were decided on and written down before the audit project was started.

Fifteen practices had consulted published work before setting their standards, of which 11 adopted best known clinical practice - for example, national asthma guidelines. One practice had referred to industry standards (for example, for telephone access); three practices had derived their standards from previous experience; two used normative values; and the remaining 41 devised their own standards.

\section{Data collection}

Half of the 71 audit projects collected data prospectively (table 5). Most of the 35 retrospective projects had used either the medical

Table 3 Relation between Oxford criteria of practices' best ever audits and practice characteristics. Values are numbers of practices unless stated otherwise

\begin{tabular}{|c|c|c|c|c|c|c|c|}
\hline \multirow[t]{2}{*}{ Practice characteristic } & \multicolumn{5}{|c|}{ Oxford criteria } & \multirow{2}{*}{$\begin{array}{c}\text { Mean Oxford score } \\
(95 \% \text { confidence } \\
\text { interval })^{\star}\end{array}$} & \multirow[t]{2}{*}{$p$ Value $\dagger$} \\
\hline & No audit & Planning & Potential & Partial & Full & & \\
\hline $\begin{array}{l}\text { Audit enthusiast: } \\
\text { Absent } \\
\text { Present }\end{array}$ & $\begin{array}{r}25 \\
6\end{array}$ & $\begin{array}{l}5 \\
5\end{array}$ & $\begin{array}{r}7 \\
13\end{array}$ & $\begin{array}{l}11 \\
38\end{array}$ & $\begin{array}{r}6 \\
33\end{array}$ & $\begin{array}{l}1 \cdot 4(1.0 \text { to } 1 \cdot 8) \\
2.9(2 \cdot 7 \text { to } 3 \cdot 2)\end{array}$ & $<0.0001$ \\
\hline $\begin{array}{l}\text { Practice manager: } \\
\text { Absent } \\
\text { Present }\end{array}$ & $\begin{array}{l}18 \\
15\end{array}$ & $\begin{array}{l}2 \\
8\end{array}$ & $\begin{array}{r}4 \\
17\end{array}$ & $\begin{array}{r}5 \\
41\end{array}$ & $\begin{array}{r}4 \\
38\end{array}$ & $\begin{array}{l}1.2(0.7 \text { to } 1.8) \\
2.7(2.4 \text { to } 2.9)\end{array}$ & $<0.0001$ \\
\hline $\begin{array}{l}\text { Computerisation: } \\
\text { None } \\
\text { Administration only } \\
\text { Administration and patient care }\end{array}$ & $\begin{array}{r}17 \\
9 \\
7\end{array}$ & $\begin{array}{l}2 \\
3 \\
4\end{array}$ & $\begin{array}{r}2 \\
4 \\
14\end{array}$ & $\begin{array}{r}9 \\
15 \\
21\end{array}$ & $\begin{array}{r}4 \\
10 \\
27\end{array}$ & $\begin{array}{l}1.4(0.9 \text { to } 2 \cdot 0) \\
2 \cdot 3(1.9 \text { to } 2 \cdot 8) \\
2 \cdot 8(2.5 \text { to } 3 \cdot 1)\end{array}$ & $<0.0001(r=0.31)$ \\
\hline $\begin{array}{l}\text { Organisation of notes: } \\
\text { None } \\
\text { Partial } \\
\text { Full }\end{array}$ & $\begin{array}{r}13 \\
3 \\
6\end{array}$ & $\begin{array}{l}3 \\
1 \\
2\end{array}$ & $\begin{array}{l}5 \\
4 \\
8\end{array}$ & $\begin{array}{r}9 \\
16 \\
13\end{array}$ & $\begin{array}{r}5 \\
13 \\
12\end{array}$ & $\begin{array}{l}1 \cdot 7(1 \cdot 2 \text { to } 2 \cdot 2) \\
3 \cdot 0(2 \cdot 6 \text { to } 3 \cdot 3) \\
2 \cdot 6(2 \cdot 1 \text { to } 3 \cdot 0)\end{array}$ & $0.03(r=0.20)$ \\
\hline $\begin{array}{l}\text { Training practice: } \\
\text { No } \\
\text { Yes }\end{array}$ & $\begin{array}{r}33 \\
0\end{array}$ & $\begin{array}{r}10 \\
0\end{array}$ & $\begin{array}{r}18 \\
4\end{array}$ & $\begin{array}{r}39 \\
7\end{array}$ & $\begin{array}{l}24 \\
18\end{array}$ & $\begin{array}{l}2 \cdot 1(1 \cdot 8 \text { to } 2 \cdot 4) \\
3.5(3.2 \text { to } 3.8)\end{array}$ & $<0.0001$ \\
\hline $\begin{array}{c}\text { No of partners: } \\
\quad 1 \\
\geqslant 2\end{array}$ & $\begin{array}{r}24 \\
9\end{array}$ & $\begin{array}{l}4 \\
6\end{array}$ & $\begin{array}{r}3 \\
19\end{array}$ & $\begin{array}{l}15 \\
34\end{array}$ & $\begin{array}{r}6 \\
36\end{array}$ & $\begin{array}{l}1 \cdot 5(1 \cdot 1 \text { to } 2 \cdot 0) \\
2 \cdot 8(2 \cdot 6 \text { to } 3 \cdot 0)\end{array}$ & $<0.0001$ \\
\hline
\end{tabular}

$\star$ No audit $=0$, planning $=1$, potential $=2$, partial $=3$, and full $=4$. 
Table 4 Participation of practice staff at different stages of 71 audit projects. Values are numbers of projects

\begin{tabular}{lccccc}
\hline Category of staff & \multicolumn{4}{c}{ Stage of audit project } \\
\cline { 2 - 6 } & $\begin{array}{c}\text { Choose } \\
\text { topic }\end{array}$ & $\begin{array}{c}\text { Set } \\
\text { standards }\end{array}$ & $\begin{array}{c}\text { Collect } \\
\text { data }\end{array}$ & $\begin{array}{c}\text { Analyse } \\
\text { data }\end{array}$ & $\begin{array}{c}\text { Propose and } \\
\text { implement change }\end{array}$ \\
\hline General practitioner(s) alone & 34 & 22 & 26 & 26 & 26 \\
Practice manager alone & 14 & 6 & 22 & 18 & 6 \\
Receptionist(s) alone & 4 & 4 & 9 & 2 & 1 \\
Practice nurse(s) alone & 4 & 9 & 4 & 2 & 0 \\
General practitioner, practice manager, and others & 11 & 20 & 9 & 21 & 22 \\
External to practice & 4 & 10 & 1 & 0 & 11 \\
Not applicable & 0 & 0 & 0 & 0 & 22 \\
\hline
\end{tabular}

records or a disease register. No audits had entailed peer review.

Sixteen projects took samples of the populations under study. Eleven of them used a consecutive series; one project used a random selection method from patients' notes; one project used a systematic sample of every fifth patient attending surgery in a specified period; and three projects used a convenience sample with no attempt to avoid bias. No project used an age-sex register to sample data. The 55 other projects had targeted the whole population under study.

\section{Presentation of results}

The results in 50 of the 71 audit projects had been analysed and a written summary had been produced, usually as percentages in tables or in text. In 20 of the 71 audits the analyses had been completed but not written up owing to lack of time (15) or because the staff were all aware of the results and a written presentation was thought to be unnecessary (five). In one audit the analysis was incomplete.

The results of the 70 audits with analysis were made known to staff at practice meetings or presentations in 55 cases and by informal communciation in the 15 other practices.

\section{Changes intended as a result of audit}

In 10 audit projects performance met the standards set, but in 56 projects results were worse than the standards set or expected; in five projects performance could not be compared with standards.

Sixty two of the 71 practices decided to make changes as a result of the audit, but in four cases these were not set in motion because the resources were unavailable (three practices) or the staff were uncertain as to how to proceed (one practice). Fifty five of the 56 practices in which standards were not met decided on changes. Table 6 outlines the modifications that were made in the 62 practices that decided to make changes. Alterations to tasks rather than people or technology were the most

Table 5 Method of data collection used in 71 audit projects

\begin{tabular}{lc}
\hline Method & No of practices \\
\hline Prospective & 24 \\
Prospective data recording & 24 \\
Patient survey by questionnaire & 11 \\
Patient survey by interview & 1 \\
Retrospective & \multicolumn{2}{c}{35} \\
Medical records & 17 \\
Disease register & 10 \\
Administrative data & 3 \\
Registration data & 1 \\
External data & 1 \\
Other & 3 \\
\hline
\end{tabular}

common. Written plans for change were made in 40 of the 62 practices.

Success of changes made

Of the 58 practices that had made changes as a result of the audit, 25 practices had performed a formal reaudit and another $28 \mathrm{had}$ informally monitored the results of changes made; the remaining five had not carried out a review (in three cases too little time had elapsed since instituting changes). In 35 of the 53 practices that had reviewed their changes $(66 \%)$, the original set standards had been reached; in 18 practices they had not been reached.

Besides the improvements in the activity associated with the audit, 67 practices reported other benefits. The most frequent advantages cited were education ( 35 practices), increased awareness (15), improved communications (13), and increased teamwork (16).

\section{Discussion}

AUDIT ACTIVITY IN STAFFORDSHIRE

Twenty four per cent of the Staffordshire practices who participated in the studies had never done any audit - a proportion comparable to the $21 \%$ of Oxfordshire practices surveyed in $1991 .^{1}$ The true proportion of practices that have never undertaken any audit may in fact be higher, because the $20 \%$ of practices that declined to participate may have had lower levels of audit activity. Only 44 out of the 151 practices visited $(29 \%)$ had completed a full audit according to the Oxford classification system.

A strong correlation was found between a practice's most complete audit project on the Oxford classification and the presence of a person in the practice who willingly took the lead on audit - a correlation that is not surprising. There were also strong correlations with the presence of a practice manager, with increasing degrees of computerisation and organisation of the notes, with being a training practice, and with partnerships as opposed to singlehanded practices. All of these organisational factors associated with audit

Table 6 Types of modifications made in 71 practices as result of audit

\begin{tabular}{lc}
\hline & No of practices \\
\hline Modification made to: & \\
Task & 34 \\
People & 5 \\
Technology & 3 \\
Task and people & 13 \\
Task, people, and technology & 3 \\
Change abandoned & 4 \\
No change decided & 9 \\
\hline
\end{tabular}


activity. (except for the number of partners) might be said to be characteristics of a well run practice. Many of these factors are correlated with each other, and it is impossible to tease out which factors are the most crucial in facilitating audit. However, these correlations may still help to identify which practices would most benefit from educational and funding support for audit.

The audit score based on the Oxford criteria that was used in table 3 and in the text was calculated on the basis that the Oxford criteria are evenly spaced in value. We think that this assumption allows mean scores and their confidence intervals to be calculated, so providing an informative summary of the raw data to aid comparison of the different subgroups of practices.

QUALITY OF COMPLETED AUDITS

The research assistant visited all of the Staffordshire practices that had completed at least one audit project and had agreed to participate. This amounted to only 71 out of the 189 Staffordshire practices because of the unwillingness of some practices to cooperate and because considerable numbers had never done audit or had only just started on a project. There was evidence of a misunderstanding of the nature of medical audit, in that some practices that claimed to be carrying out audit were discovered on a visit to have been only collecting data - for example counting the number of laboratory tests ordered and the proportion of abnormal test results - without trying to set standards from, draw conclusions from, or make any changes on the basis of the data.

The 71 projects reviewed were the best that had been performed in the view of the practice. No information was collected on the other projects that the practices had completed, or had abandoned before completion, but these are likely to be of a lower standard. Our method of data collection is thus likely to exaggerate the overall quality of the current audit activity in Staffordshire.

One prerequisite for successful change is the participation and commitment of all those affected. ${ }^{78}$ In our study general practitioners were the main movers in most of the stages of the projects, and yet the changes made as a result of the audit projects were mainly modifications of staff tasks. General practitioners have traditionally taken an authoritarian approach to the running of their practices, but they will need to allow and encourage staff to participate in evaluating practice performance and deciding solutions if staff are going to be committed to making changes.

The 71 projects studied a variety of important subjects, and we found little to criticise in the choice of topic. The setting of standards was less in keeping with recommended principles in that one sixth of practices had not set standards, one half had not written explicit standards, and three fifths had used arbitrary standards. Scientific principles of sampling had been ignored in some cases. ${ }^{17}$ None of the audit projects had entailed peer reviews, despite the medical audit advisory group's encouragement and willingness to facilitate it. The results of most practice audits seem to have been clearly presented and disseminated to the practice team.

In only 10 of the projects had the performance satisfied the standards set, and most of the practices decided to make changes as a result of the project. In most cases, the changes were to tasks carried out - for example, allocating a receptionist to answer the phone at peak times, and increasing the availability of appointment for patients to see a doctor on the same day as telephoning. When the changes were evaluated the original standards had been met in most cases, which is further good evidence of the value of medical audit.

HOW SHOULD THE QUALITY OF AUDIT IN PRIMARY CARE BE EVALUATED?

The original reasons for developing the Oxford classification system were to offer formative assessment for practices to help them improve their audits and to provide summative assessment for the family health services authority to satisfy the needs for professional accountability. ${ }^{1}$ Many medical audit advisory groups have adopted the Oxford classification system as an indicator of the quality of audit activity, ${ }^{212} 13$ but they should be aware of the limitations of the classification and be wary of using it as their sole way of assessing audits. The Oxford system does not include an assessment of the importance or relevance of the audit topic. A good audit project will often be based on a problem that has been identified in the practice and in which change is possible, but this important step of identification of a remediable problem is also not included in the Oxford system. Furthermore, an important indicator of the success of an audit project will be whether improvements in patient care resulted. More than half of the practices that had reviewed the results of the changes resulting from their audits had done so by an informal monitoring process, and this is likely to be more cost effective than a rigorous repetition in a formal reaudit, bearing in mind the limitations in time and resources available for audit.

We suggest that the following framework is used for detailed assessment of the quality of medical audit in primary care.

- Was the choice of topic appropriate (one aimed at a priority area such as a recognised problem within the practice or a topic of national importance)?

- Was a sound scientific method used?

- Were changes implemented to resolve any problems found?

- Were the changes monitored?

We thank all medical colleagues who participated in the study. The project was funded by the Department of Health.

1 Derry J, Lawrence M, Griew K, Anderson J, Humphreys J, Pandher KS. Auditing audits: the method of Oxfordshire Medical Audit Advisory Group. BMF 1991;303:1247-9. Williams H, Beaton SA. Auditing audits. Quality in Health Care 1992;1:206-7.

3 Walshe K, Coles J. Medical audit: in need of evaluation. Quality in Health Care 1993;2:189-90. 
4 Department of Health. Medical audit in the family practitioner services. London: DoH, 1990. (Health circular $\mathrm{HC}(\mathrm{FP})(90) 8$.)

5 Jones R, Spencer J. Making changes? Audit and research in general practice. Br f Gen Pract 1993;43:359-60.

6 Department of Health. Working for patients. Working paper 6. London: HMSO, 1989.

7 Scott MGB, Marinker, M. Imposed change in general practice. $B M \mathcal{F}$ 1992;304:1548-50.

8 Pringle $M$. Managing change in general practice: introduction. $B M F$ 1992;304:1357-8.

9 Kerrison S, Packwood T, Buxton M. Medical audit: taking stock. Respondents' views of the factors inhibiting audit. London: King's Fund Centre, 1993. (Medical audit series No 6, appendix 1.)
10 Smith R. Audit and research. BMF 1992;305:905-6.

11 Barton AG, Thomson RG. Is audit bad research? Audit Trends 1993;1:51-3.

12 Humphrey C, Berrow D. Developing role of medical audit advisory groups. Quality in Health Care 1993;2:232-8.

13 Birmingham Medical Audit Advisory Group. Annual report. Birmingham: Guy Houghton, 1993.

14 Royal College of Physicians of London. Medical audit. A first report. What, why and how? London: Royal College of report. What, why

15 Moses LE, Emerson JD, Hosseini $\mathrm{H}$. Analysing data from ordered categories. N Engl f Med 1984;311:442-8.

16 Altman DG. Practical statistics for medical research. London: Chapman and Hall, 1991.

17 Campbell MJ. Sample sizes in audit. BMF 1993;307:735-6. 